\title{
Multi-compartment chemical characterization and risk assessment of chemicals of emerging concern in freshwater systems of western Kenya
}

Faith Jebiwot Kandie ${ }^{1,2,3,4}$, Martin Krauss' ${ }^{1}$, Riccardo Massei ${ }^{1,8}$, Akbar Ganatra $^{2,5}$, Ulrike Fillinger ${ }^{2}$, Jeremias Becker ${ }^{6,7}$, Matthias Liess ${ }^{6,7}$, Baldwyn Torto ${ }^{2}$ and Werner Brack, ${ }^{1,3}$ (1)

\begin{abstract}
Background: Within the last decades, there has been increasing research on the occurrence of chemicals of emerging concern (CECs) in aquatic ecosystems due to their potential adverse effects on freshwater organisms and risk to human health. However, information on CECs in freshwater environments in sub-Saharan countries is very limited. Here, we investigated the occurrence of CECs in snails and sediments collected from 48 sites within the Lake Victoria South Basin, Kenya, which have been previously investigated for water contamination. Samples were analyzed by liquid chromatography coupled to high-resolution mass spectrometry (LC-HRMS) with a target list of 429 compounds.

Results: In total, 30 compounds have been detected in snails and 78 in sediment samples, compared to 79 previously identified compounds in water. By extending the monitoring of CECs to snails and sediments, we found 68 compounds that were not previously detected in water. These compounds include the anti-cancer drug anastrozole, detected for the first time in the Kenyan environment. Individual compound concentrations were detected up to $480 \mathrm{ng} / \mathrm{g}$ wet weight ( $\mathrm{N}$-ethyl-o-toluenesulfonamide) in snails and $110 \mathrm{ng} / \mathrm{g}$ organic carbon (pirimiphos-methyl) in sediments. Higher contaminant concentrations were found in agricultural sites than in areas not impacted by anthropogenic activities. Crustaceans were the organisms at greatest toxic risk from sediment contamination [toxic unit (TU) up to 0.99] with diazinon and pirimiphos-methyl driving this risk. Acute and chronic risks to algae were driven by diuron (TU up to 0.24), whereas fish were found to be at low-to-no acute risk (TU up to 0.007).

Conclusions: The compound classes present at the highest frequencies in all matrices were pesticides and biocides. This study shows substantial contamination of surface water in rural western Kenya. By filling data gaps on contamination of sediments and aquatic biota, our study reveals that CECs pose a substantial risk to environmental health in Kenya demanding for monitoring and mitigation.
\end{abstract}

Keywords: Biota, Chemicals of emerging concern, Surface water, Sediment, Toxic units, Risk assessment, Occurrence, Western Kenya

*Correspondence: werner.brack@ufz.de

${ }^{1}$ Department of Effect-Directed Analysis, Helmholtz Centre for Environmental Research (UFZ), Permoserstrasse 15, 04318 Leipzig,

Germany

Full list of author information is available at the end of the article

\section{Background}

Chemicals of emerging concern (CECs) such as pesticides, pharmaceuticals, and personal care products (PPCPs), surfactants, and other industrial chemicals are of global environmental concern due to their toxic risk on ecosystems and human health. The occurrence 
of CECs in freshwater ecosystems has been shown to cause adverse effects including long-term changes in the aquatic community composition [33]. Several studies have documented the global occurrence of CECs in freshwater resources $[3,32,35,56]$. However, most research is focused on high-income countries. Although many African laboratories are increasing their efforts to monitor the occurrence of CECs in African aquatic ecosystems [44], this research field is yet to be fully explored. Many previous studies from Kenya focused largely on urban areas with a limited number of compounds investigated $[5,17,23,25,28,47,51]$. Among the studies on pesticides in the environment, the previous work largely focused on organochlorine and organophosphates compounds [43, $50,59]$, although the next generation of pesticides including phosphoric esters and neonicotinoids are currently in use and have been found in Kenyan surface water [23]. There is a need to increase the number of compounds under research and expanding to rural areas.

When CECs are discharged into the aquatic ecosystem, they undergo equilibrium partitioning between water and sediments and may accumulate in biota according to their hydrophobicity and toxicokinetics in the organism $[2,14,21,40]$. In this context, sediments and biota act as passive samplers reflecting long- and mid-term exposure, respectively, and allow also for the detection of compounds that are hardly detectable in the water phase. Detection of contaminants in biota proves their bioavailability and bioaccumulation potential [36, 60]. Mollusks such as snails and mussels are particularly suitable as passive samplers due to their low metabolization competence $[48,49]$. Persistent organic pollutants (POPs) with a high octanol-water partitioning coefficient (log $K_{\mathrm{ow}}$ ) are particularly prone to accumulate in sediments and lipid-rich biological tissues. This results in long-term exposure particularly of benthic species and poses a substantial risk to the aquatic ecosystem [32]. Thus, a large body of literature on the bioaccumulation of legacy POPs including organochlorine pesticides, polychlorinated biphenyls (PCBs), and polycyclic aromatic hydrocarbons (PAHs) exist [20, 41]. However, currently used organic chemicals including modern pesticides are designed to be more polar and less persistent. These chemicals may still accumulate in sediments and may even pose higher toxic risks to aquatic ecosystems due to their higher bioavailability [6]. Many CECs can be considered as pseudopersistent with emission exceeding degradation rates and have been shown to accumulate in sediments and biota $[11,38]$. These chemicals are in the focus of this present study.

The objectives of this study were: (1) to investigate the occurrence and distribution of CECs in aquatic ecosystems in snails and sediments in the Lake Victoria South
Basin and to reveal whether analyzing these matrices can substantially increase the number of chemicals detected compared to the water analysis only, (2) to determine the spatial distribution of contaminants dependent on land use within the Lake Victoria South Basin, and (3) to assess risks of sediment-associated chemicals on fish, crustaceans, and algae by calculating equilibrium water concentrations from sediment concentrations. For the water phase, data were obtained from our previous study [26] and used for the comparison of compound concentrations in snail and sediments.

\section{Materials and methods \\ Chemicals}

Analytical standards were purchased from various suppliers with purity of above $97 \%$. The 429 target compounds included pesticides and biocides (PaBs), PPCPs, industrial compounds, and transformation products which have been detected in surface waters and sediments. More information on the target compounds and internal standards is presented in the Supplementary Information (Additional file 1: Tables $\mathrm{S} 1, \mathrm{~S} 2$ respectively). Methanol (LC-MS grade), ethyl acetate, dichloromethane (DCM), and acetone (all LC grade) were obtained from Sigma-Aldrich (Germany), while LC-MS grade water was purchased from Thermo-Fisher (Germany). Primary Secondary Amine (PSA), sodium chloride, and magnesium sulfate were supplied by Sigma-Aldrich.

\section{Description of the study area and sampling}

The study area was located within the Lake Victoria South Basin (LVSB) in western Kenya covering Kisii, Nyamira, Migori, Homabay, Kericho, Kisumu, and Narok counties. Sampling sites have been described in detail in Kandie et al. [26] and Becker et al. [8]. Forty-eight sites were sampled for sediments and snails between September and October 2017 in parallel to water samples analyzed previously Kandie et al. [26]. For rivers or drainage canals, 50-m transects were sampled with four sampling spots distributed equally along the transect, with bias on suitable snail habitats. For reservoirs, the four edges were taken as sampling spots in each site. Snails were sampled using a handheld stainless-steel snail catcher. Approximately $200 \mathrm{~g}$ of sediment were sampled using a pre-cleaned stainless-steel scoop, homogenized, sieved $(2 \mathrm{~mm})$, and transferred to a zip lock bag. Sediment samples were covered with aluminum foil to avoid photodegradation and immediately put into a portable freezer $\left(-4{ }^{\circ} \mathrm{C}\right)$ and transferred to $-20{ }^{\circ} \mathrm{C}$ in the laboratory. Snails were kept alive in falcon tubes for identification for 
up to $15 \mathrm{~h}$. After identification in the laboratory, the samples were stored at $-20^{\circ} \mathrm{C}$ prior to extraction.

\section{Sample preparation and extraction Snail extraction}

Snails were found in 20 out of the 48 sites sampled and separated according to sites and species. The snails sampled were from the genera Bulinus, Biomphalaria, Melanoides, Lymnaea, Physa, and Ceratophallus. The snails were found in shallow slow-moving water. Except for Physa which were much larger (approximately $3 \mathrm{~cm}$ ), all the other genus had an average size of $5 \mathrm{~mm}$. Most of the snails were attached to aquatic vegetation within streams and drainage canals. The snails from each site belonging to the same species were pooled. Chemicals were extracted from the snail tissues by applying a modified QuEChERS (Quick, Easy, Cheap, Effective, Rugged, and Safe) method as described by Inostroza et al. [22]. Briefly, $1 \mathrm{~g}$ of crushed snails was homogenized in $5 \mathrm{~mL}$ acetonitrile (LC-MS grade) using a Stuart handheld homogenizer (SHM1/UK) for $1 \mathrm{~min}$. For salting out, $2 \mathrm{~g}$ of anhydrous magnesium sulfate and $500 \mathrm{mg}$ of sodium chloride were added, vortexed immediately on highest intensity for $2 \mathrm{~min}$, and centrifuged at $3000 \times g$ for $5 \mathrm{~min}$. An aliquot $(1 \mathrm{~mL})$ of the acetonitrile phase was transferred into a pre-assembled 2-mL QuEChERS tube containing $150 \mathrm{mg}$ anhydrous magnesium sulfate and $50 \mathrm{mg}$ Primary Secondary Amine (PSA) for clean-up, vortexed on highest intensity for $1 \mathrm{~min}$, and centrifuged for $5 \mathrm{~min}$ at $17,000 \times g$. The supernatant extract was then vacuum filtered $(0.2 \mu \mathrm{m}$ PTFE Samplicity system filter, Merck Millipore, Germany) into a $1.5 \mathrm{~mL}$ autosampler vial. The filtered extract $(400 \mu \mathrm{L})$ was transferred into amber autosampler vials and stored at $-20^{\circ} \mathrm{C}$ until instrumental analysis. A method blank was prepared using water from a pristine reference stream within the Harz Mountains (Wormsgraben, Germany) and processed similar to the samples. From recovery experiments carried out in a pre-study, $80 \%$ of the compounds had recoveries between 70 and $120 \%$ showing a good overall performance of the QuEChERS method.

\section{Sediment extraction and clean-up}

Sediment samples were freeze-dried (SP Scientific, Advantage EL-85) and the sediment mass extracted was adjusted according to the total organic carbon (TOC) contents to obtain a comparable matrix load of the extracts [39]. The TOC content of the sediments was determined on a Flash 200 organic elemental analyzer coupled to a Delta V Advantage Isotope Ratio mass spectrometer (Thermo). The analyzer was operated at $1000^{\circ} \mathrm{C}$ to ensure the complete combustion. Details of the TOC procedure are described in Additional file 2: S3.

Compounds were extracted from sediments according to the method described by Massei et al. [39] with minor modifications. Briefly, pressurized liquid extraction (PLE, ASE 200 device, Dionex) was performed by taking approximately 5-10 $\mathrm{mg}$ of freeze-dried sediment (corresponding to $100 \mathrm{mg}$ of TOC content) and mixed with pure diatomaceous earth (25\% of sediment weight, Hydromatrix, Restek). This mixture was transferred to stainless-steel PLE cells fitted with $27 \mathrm{~mm}$ glass fiber filters (Dionex) and extracted at $100{ }^{\circ} \mathrm{C}$ with ethyl acetate and acetone $(50: 50, \mathrm{v} / \mathrm{v})$ in two static cycles at a pressure of 100 bar. A method blank containing only hydromatrix was prepared for each batch of samples to evaluate instrument background contamination. The extract was concentrated to $0.5 \mathrm{~mL}$ using a gentle stream of nitrogen (Xcelvap, Thermo), and the solvent was exchanged for DCM. For extract clean-up, flash chromatography was performed using a pre-packed chromatography column (Chromabond Flash RS $4 \mathrm{SiOH}, 4$ g, Macherey-Nagel) and an Agilent 1260 binary pump. Conditioning of the column was done using DCM prior to clean up. A corresponding volume of internal standard $(1 \mu \mathrm{g} / \mathrm{mL})$ was added to the concentrated sample extract in the vials (final concentration $50 \mathrm{ng} / \mathrm{mL}$ ). Using a glass pipette, the extract was transferred to the flash column for clean-up using DCM and methanol at $5 \mathrm{~mL} / \mathrm{min}$ (Additional file 2: S4) and collected in separate vials. The DCM and methanol fractions were combined $(50: 50, \mathrm{w} / \mathrm{w})$ and concentrated to $1 \mathrm{~mL}$ using a gentle stream of nitrogen while rinsing the vial walls with methanol and blowing down to $0.5 \mathrm{~mL}$ to exchange the solvent completely for methanol.

\section{Instrumental analysis}

Aliquots of $100 \mu \mathrm{L}$ snail extracts were transferred into $2 \mathrm{~mL}$ vials with insert together with $10 \mu \mathrm{L}$ of internal standard mix $(1 \mu \mathrm{g} / \mathrm{mL})$ containing 40 isotope-labeled compounds (Additional file 1: Table S2). Eleven methodmatched calibration levels were prepared ranging from 0.05 to $500 \mathrm{ng} / \mathrm{mL}$ in vial. For the calibration samples, an appropriate volume of the standard solution was added to $1 \mathrm{~mL}$ of water and processed in the same way as the samples.

Sediment extracts were analyzed in $100-\mu \mathrm{L}$ aliquots transferred to a $2-\mathrm{mL}$ vial with insert. Method-matched calibrations were prepared at 12 concentration levels corresponding to 0.2 to $2000 \mathrm{ng} / \mathrm{mL}$ in vial by adding standard solutions to $5 \mathrm{~mL}$ of ethyl acetate:acetone $(50: 50 \mathrm{v} / \mathrm{v})$ to mimic the PLE extracts. The solvent was evaporated using a gentle stream of nitrogen (Xcelvap, Thermo) and exchanged to DCM. Calibration solutions were subjected 
to clean up with flash chromatography after adding $50 \mu \mathrm{L}$ of internal standard $(50 \mathrm{ng} / \mathrm{mL})$.

All the samples were analyzed using liquid chromatography (Thermo Ultimate 3000 LC) coupled with highresolution mass spectrometry (QExactive Plus, Thermo) equipped with a heated electrospray ion source. Snail and sediment extracts were analyzed by injecting $10-\mu \mathrm{L}$ and $5-\mu \mathrm{L}$ aliquots into the instrument, respectively. Instrument settings and the chromatographic conditions have been described by Kandie et al. [26]. A water (A) and methanol (B) solvent gradient, both with $0.1 \% \mathrm{v} / \mathrm{v}$ formic acid, was applied in separate positive and negative ionization analytical runs. A combination of full scan $(\mathrm{m} / \mathrm{z}$ range 100-1500) at a nominal resolving power of 70,000 (referenced to $\mathrm{m} / \mathrm{z} 200$ ) and data-independent MS/MS fragmentation at a resolving power of 35,000 was used for both positive and negative modes. The mass spectrometer settings are described in Kandie et al. [26].

\section{Risk assessment based on toxic units (TU)}

The ecotoxicological relevance of the obtained compound concentrations was evaluated by performing risk assessment based on toxic units (TU) [55]. Equilibrium water concentrations $\left(C_{\text {ewsed }}\right)$ were derived from concentrations in sediment organic carbon $\left(C_{\text {sed }}\right)$ assuming equilibrium partitioning (Eq. 1). Organic carbon-water partitioning coefficients $\left(K_{\mathrm{oc}}\right)$ were derived using linear solvation energy relationships (LSER) applying the open access UFZ-LSERs database [58] as described by Inostroza et al. [21]:

$$
C_{\text {ewsed }}=\frac{C \text { sed }}{K \text { oc }} .
$$

The TU was calculated for each chemical by normalizing the equilibrium water concentrations $\left(C_{\text {ewsed }}\right)$ to the effect concentrations (EC) for fish, crustaceans, and algae according to Eq. 2. Effect concentrations were derived from Busch et al. [10]. The EC values were retrieved from United States Environmental Protection Agency's (USEPA) ECOTOX database and were based on the 5th percentile of measured acute values [10], predicted readacross, or ECOSAR:

$$
\text { Toxic unit }(\mathrm{TU})=\frac{\mathrm{C}_{\text {ewsed }}}{\mathrm{EC}}
$$

The calculated TUs were compared to acute and chronic risk threshold values as proposed by Malaj et al. [37]. The acute risk thresholds (ART) for all organisms are 0.1 Tus, while chronic risk thresholds (CRT) for fish (0.01 TUs), Daphnia (0.001 TUs), and algae (0.02 TUs) were applied.
To predict mixture toxicity, individual TU values were summed up $\left(\mathrm{TU}_{\text {sum }}\right)$ based on the concentration addition (CA) model [34] designed for compounds with similar mode of action $[1,13]$ but being also a reasonable estimate for mixtures of environmental compounds without knowing their individual modes of action [4].

\section{Data analysis}

Peak detection and annotation of target compounds were performed using MZmine (Version 2.38), [54], and detected target compounds were further confirmed and quantified using TraceFinder 4.1 (Thermo). The MZmine and TraceFinder settings were applied as shown in Kandie et al. [26]. Jchem was used for structure-based determination of compound properties including molecular formula and exact mass. The method detection limits (MDLs) were determined using calibration standards based on USEPA (2011) guidelines. Graphs and statistical analysis were performed using Microsoft Excel 2013 and SigmaPlot 13.0.

\section{Results and discussion \\ Body burden of pollutants in snails}

Out of the 429 compounds targeted, 30 compounds including PaBs, PPCPs, and industrial compounds were detected in snail tissues (Fig. 1). Concentrations detected in snail tissues on wet weight basis (ng/g ww) are given in Additional file 1: Table S5 and Additional file 2: Figure S1.

Almost two-thirds of the chemicals detected in snails were $\mathrm{PaBs}$ with 19 out of 30 compounds (Fig. 1). Atrazine, a pre-emergence and post-emergence herbicide still in use in Kenya for the control of broadleaf weeds and grasses, was detected in $95 \%$ of the snail samples followed by the insect repellant diethyltoluamide (DEET) with 93\%. The frequent detection of DEET may be explained by the high mosquito infestation and the high prevalence of malaria infecting 20 to $40 \%$ of the population in counties within the lake endemic region of western Kenya [7]. DEET is used as a topical insect repellant for the control of mosquitoes. It could be released into the water when performing water-related activities such as taking a bath in the rivers and reservoirs [57], a common practice which was observed during sampling in the region. Individual pesticide concentrations ranged from 0.2 to $375 \mathrm{ng} / \mathrm{g}$ ww with maximum concentrations found for the herbicide atrazine at $375 \mathrm{ng} / \mathrm{g} \mathrm{ww}$, the fungicide bupirimate at $97 \mathrm{ng} / \mathrm{g} \mathrm{ww}$, and the insecticide diazinon (37 ng/g ww). The neonicotinoids, acetamiprid, and imidacloprid were present in the snail tissues in concentrations up to $27 \mathrm{ng} / \mathrm{g}$ ww and $21 \mathrm{ng} / \mathrm{g}$ ww, respectively.

Among PPCPs, temazepam (98\%) and 2-hydroxyquinoline (78\%) had the highest detection frequencies (Fig. 1). 


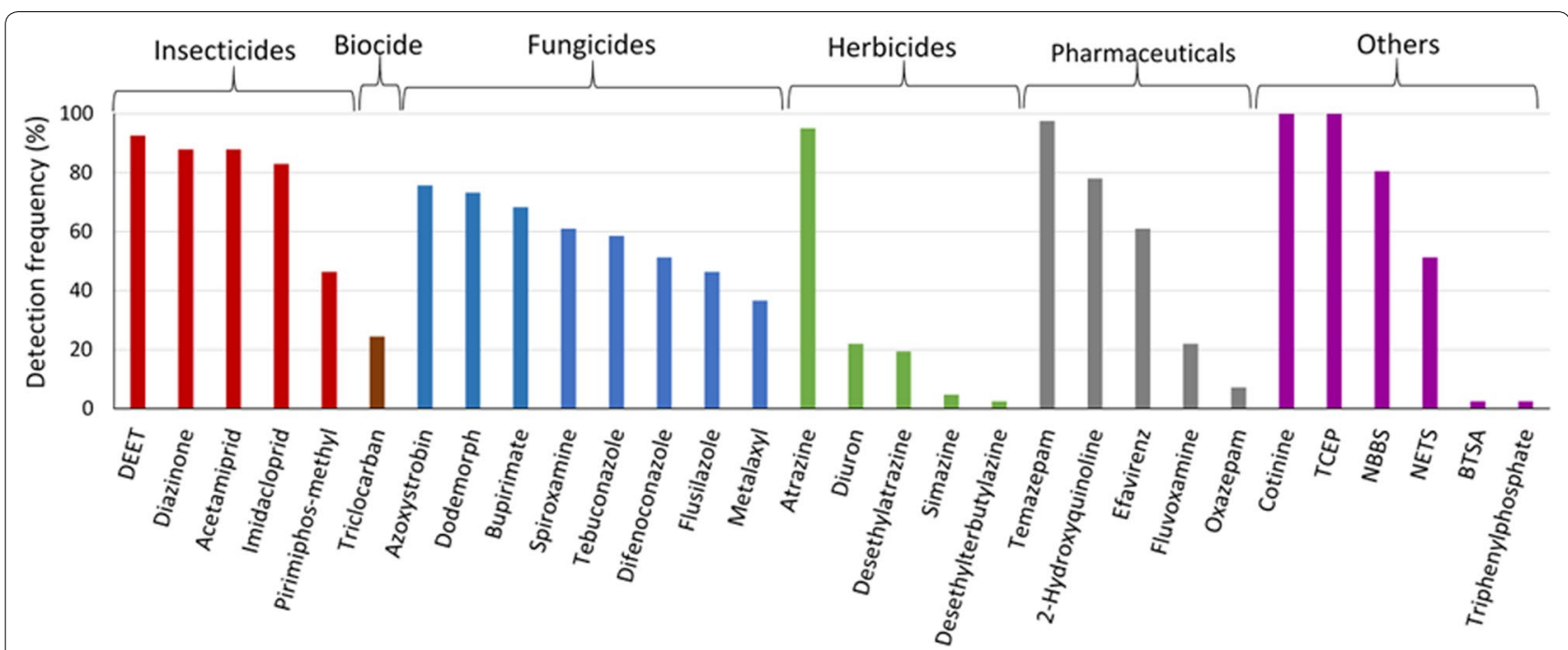

Fig. 1 Frequency of detection for compounds in snail tissue samples from the Lake Victoria South Basin. TCEP: Tris(2-chloroethyl)phosphate; NBBS: N-butylbenzenesulfonamide; NETS: N-ethyl-o-toluenesulfonamide; BTSA: 2-benzothiazolesulfonic acid

Individual compound concentrations ranged from 0.8 to $137 \mathrm{ng} / \mathrm{g}$ ww. Maximum concentrations were recorded for efavirenz (137 ng/g ww) and 2-hydroxyquinoline (115 ng/g ww). This highest concentration for efavirenz was found in PS28 (Additional file 2: Figure S1) located within Kisumu County, and could be attributed to the high HIV/AIDS prevalence (16.3\%) and the access to antiretroviral therapy (ART) with a coverage of 90\% [45] in the region. Efavirenz is a non-nucleoside reverse transcriptase inhibitor (NNRTI) used in combination with the other medications as antiretroviral treatment for HIV/AIDS [31].

Plasticizers and flame retardants were also present in snail tissues with highest detection frequencies reported for tris(2-chloroethyl)phosphate (100\%) and N-butylbenzenesulfonamide (NBS, 80\%). Individual compound concentrations ranged from 2.8 to $481 \mathrm{ng} / \mathrm{g}$ ww. The highest concentration was found for $\mathrm{N}$-ethyl-o-toluene sulfonamide (NETS, $481 \mathrm{ng} / \mathrm{g} \mathrm{ww}$ ), a compound with widespread use in industrial products and as an ingredient to pesticide formulations. In addition, cotinine was present in all the snails sampled (detection frequency 100\%) with concentrations up to $311 \mathrm{ng} / \mathrm{g}$ ww (Additional file 2: Figure S1). Due to the compound being the most abundant metabolite of nicotine, its high stability, and half-life, cotinine has been suggested to be the ideal biomarker of tobacco exposure and smoking status [53]. Cotinine is excreted by human mainly through the urine and may end up in surface water through effluent discharge of domestic waste.

Variability in compound concentrations was observed in the different snail species sampled from the same site.
Example sites include PS17 and PS28 (Additional file 2: Figure S1) where total concentrations in Ceratophallus sp. and Melanoides tuberculata were lower than those in other species. A plausible explanation for this observation may be different lipid contents and age which could not be considered during sample preparation. A study carried out by Duncan et al. [15] noted considerable variation in total lipid for Biomphalaria glabrata (5\%) and $B$. alexandrina (2\%) snails and, in addition, intraspecific differences in total lipids (1-10\%) in B. glabrata. Since most pollutants accumulate primarily in lipid tissue, variation in lipid content may lead to differences in the body burden of contaminants.

The predators of the snails investigated in this study include cray fish (Procambarus alleni), water bug (Belostoma flumineum), waterfowl, and cichlid fishes [19, 42]. These predators could biomagnify and bioaccumulate certain contaminants during feeding resulting in elevated levels of contaminants in the food chain. The consumption of contaminated food is a major source for xenobiotics in predating birds and mammals [46]. The effects of pesticide exposure in birds have been linked to neurotoxicity and endocrine disruption [29]. Other effects of pesticides include impaired foraging and chick rearing, eggs shell thinning, and reproductive failure [29]. In a study carried out by Guo et al. [18] on compound prioritization based on potential of secondary poisoning in fish-eating birds and mammals, diazepam was ranked the highest (risk score 0.1-1) among the pharmaceuticals tested. In addition, gregarious animals including fish and birds could biomagnify and bioaccumulate contaminants 


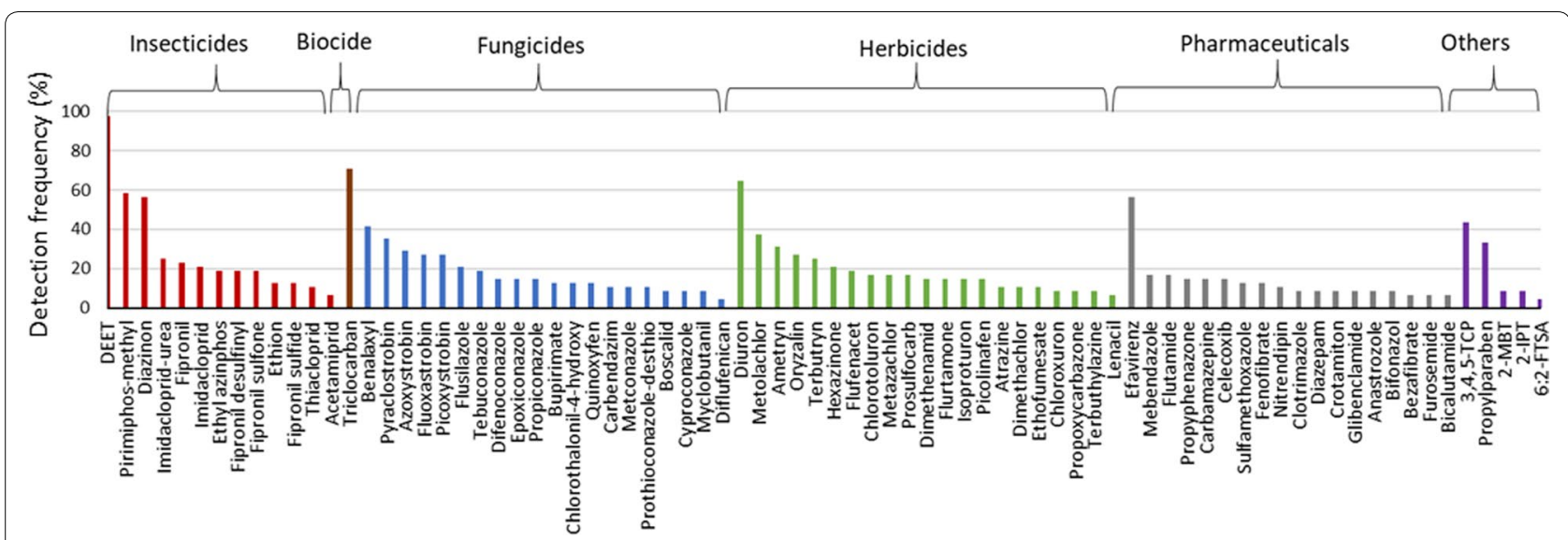

Fig. 2 Frequency of detection for compounds in sediment samples from the Lake Victoria South Basin. 3,4,5-TCP: 3,4,5-trichlorophenol; 2-MBT: 2-morpholinothiobenzothiazole; 2_IPT: 2-Isopropylthioxanthone; 6:2-FTSA: 6:2-fluorotelomer sulfonic acid

and then migrate becoming a predominant pathway for contaminants in the environment [9].

\section{Occurrence and distribution of pollutants in sediments}

Out of the 429 targeted compounds analyzed in the sediment samples from the LVSB, 78 compounds were detected (Fig. 2 and Additional file 1: Table S6).

Similar to snail samples, PaBs were the dominant chemical class with $71 \%$ of compounds detected in the sediments. Compounds frequently detected included DEET (98\%), triclocarban (71\%), diuron (65\%), pirimiphos-methyl (58\%), and diazinon (56\%) (Fig. 2). Highdetection frequencies of diazinon and pirimiphos-methyl are in line with a study performed by Musa et al. [43] who noted that diazinon and pirimiphos-methyl were among the commonly used pesticides in the Nyando catchment area which is within the LVSB. Individual compound concentrations reached up to $111 \mathrm{ng} / \mathrm{g}$ organic carbon (OC) with highest concentrations recorded for pirimiphosmethyl (111 ng/g OC), diuron (93 ng/g OC), and DEET (68 ng/g OC) (Fig. 3). Pirimiphos-methyl is a broadspectrum insecticide used for the control of pest during storage. In addition, it is approved as an insecticide for indoor spraying against mosquitoes, cockroaches, and houseflies [52]. Diuron is a selective herbicide for the control of weeds in sugarcane plantations. Concentrations reported in this study are within the range reported in a review by K'oreje et al. [24] on the occurrence of pesticides in African river sediments.

A total of 19 PPCPs were detected with frequencies ranging from $6 \%$ (bezafibrate) to $56 \%$ (efavirenz). We also found the preservative propylparaben (33\%) and the anti-cancer drug anastrozole (8\%). To the best of our knowledge, this is the first study to report anastrozole occurrence in Kenyan aquatic ecosystems. The detection of anastrozole could be linked to the rising diagnoses and treatment of breast cancer in the continent and particularly in Kenya [16]. Anastrozole is applied for hormone therapy during breast cancer treatment. The highest PPCP concentrations were detected for efavirenz with up to $29 \mathrm{ng} / \mathrm{g}$ OC. Other compounds detected at higher concentrations include crotamiton (1.8 ng/g OC) and diazepam $(1.5 \mathrm{ng} / \mathrm{g} \mathrm{OC})$. The concentrations of the antibiotic sulfamethoxazole measured in this study $(0.21 \mathrm{ng} / \mathrm{g}$ OC) fall below the concentrations reported by Kairigo et al. [25] in sediments from Mwania river in Kenya by about one order of magnitude. This is probably due to differences in consumption patterns and the impact of municipal waste in the study area, since their study was performed in an urban setting.

\section{Comparison of the incidence of CECs in different environmental matrices of western Kenya}

The chemical data from the present study were compared with the compounds found in the water phase in Kandie et al. [26]. In total, 142 compounds were detected in the study area with 79 compounds in water (Additional file 2: Figure S2), 30 compounds in snails, and 78 compounds in sediments. Among these compounds, only nine were common in all three matrices (Fig. 4) including acetamiprid, atrazine, azoxystrobin, DEET, diazinon, diuron, imidacloprid, pirimiphos-methyl, and triclocarban. Although these compounds were present in all matrices, their ranking with respect to detection frequency and concentrations in the individual matrices was quite different. For example, atrazine and diazinon were among the compounds frequently detected at high concentrations in biota, whereas this was not the case in water and sediments. As expected, rather hydrophobic compounds 


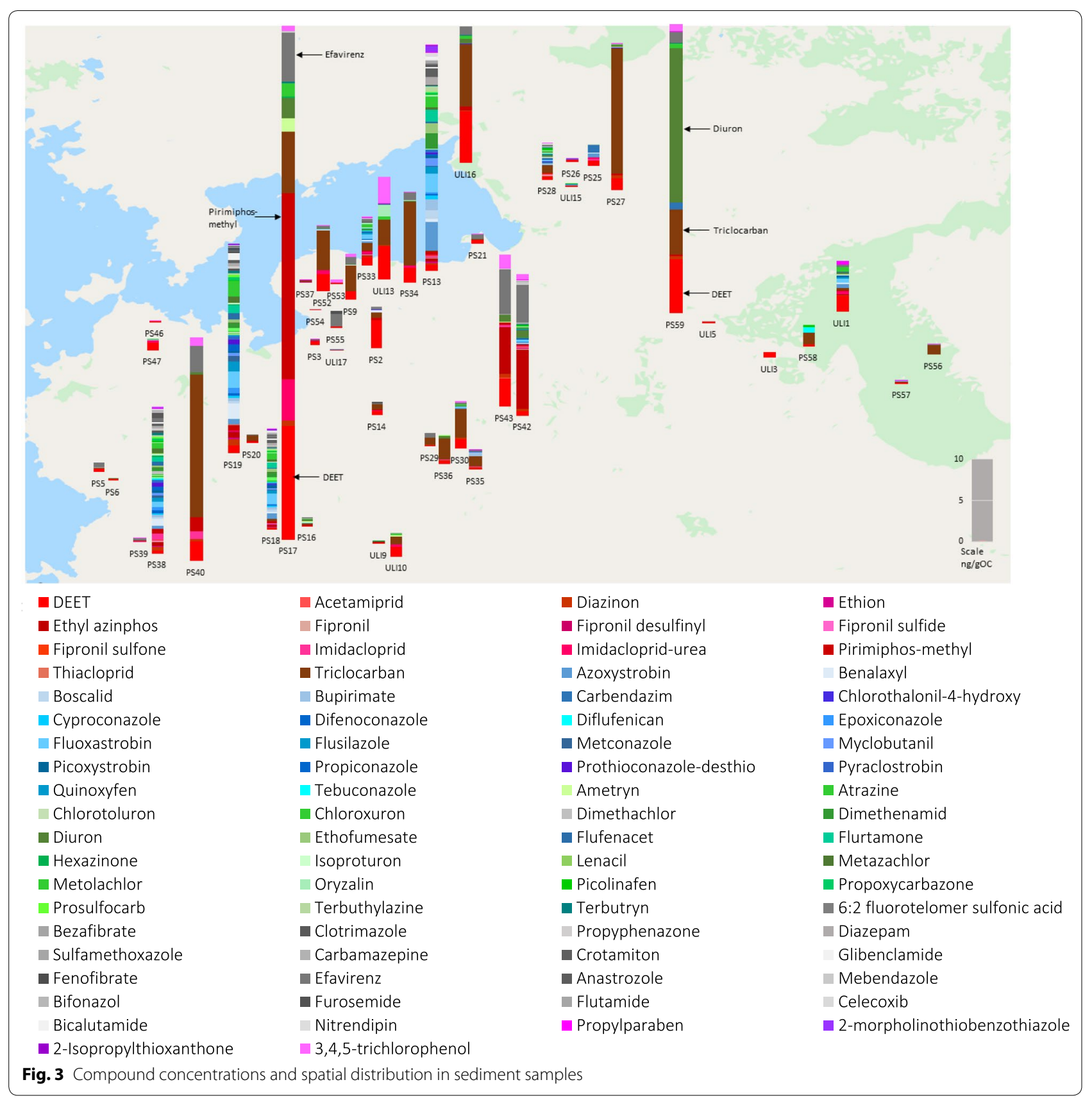

such as pirimiphos-methyl ( $\left.\log K_{\mathrm{ow}} 4.12\right)$ were found in higher concentrations in sediments and snails (PS17) than in water.

Correlations between concentrations in water, snails, and sediments have been found only for a few compounds. The strongest correlation was obtained for pirimiphos-methyl $(r=0.53)$ for concentrations in sediments and snails followed by water and snail concentrations of DEET $(r=0.35)$ and diazinon $(r=0.31)$ in sediment and water. The low correlations observed between biota and the other matrices suggest a quite complex bioaccumulation regime involving different uptake pathways [12], complex temporal exposure patterns (e.g., due to pesticide peaks), and high small-scale variance of exposure.

Among the compounds present, 54 compounds in sediments, 51 in water, and 7 in snails were specific to the individual phases (Fig. 4), indicating the need to consider different complementary matrices to get a more comprehensive picture of contamination. As an example, the pharmaceutical efavirenz and fungicides difenoconazole, 


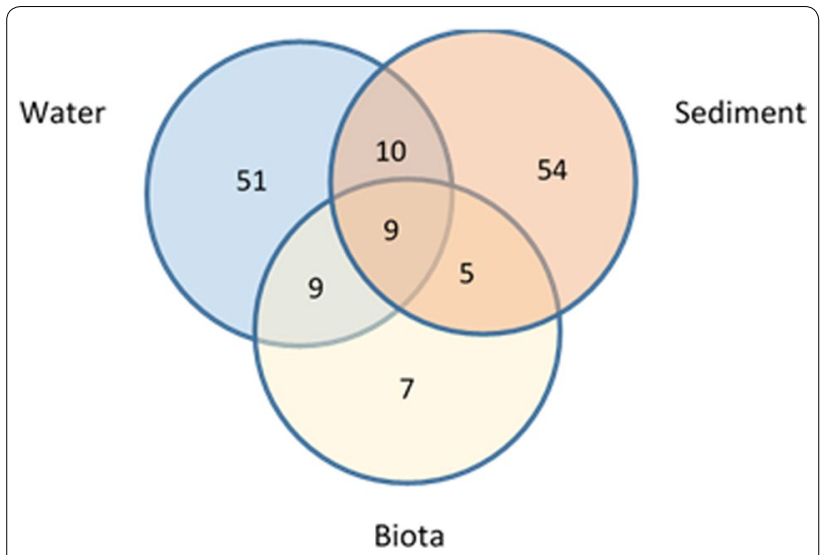

Fig. 4 Numbers of detected compounds in water, sediment, and snail samples within the study area

bupirimate, flusilazole, and tebuconazole were not detected in grab water samples, but could be quantified in snail and sediment samples. Efavirenz is moderately hydrophobic $\left(\log K_{\mathrm{ow}}=4.7\right)$ and is likely to partition to snail and sediment phases. Also, the snapshot character of water samples or the need for enrichment to exceed detection limits could influence compound detections. In addition, the intermittent release of chemicals into the environment through a run-off event after spraying or emission events could influence the presence of a compound in the aquatic environment.

\section{Impact of land use on contamination patterns in different environmental compartments}

Among the 48 sampling sites, 17 sites could be clearly connected to specific land uses (Additional file 2: Figure S3), including agricultural areas (i.e., sugarcane, tea, and rice) and reservoirs characterized by low anthropogenic inputs. The other sites showed mixed land-use patterns and were not taken into consideration. Overall, sugarcane growing areas showed the highest concentrations of PaBs of all investigated types of land use (Fig. 3, Additional file 2: Figures S1-S3).

Sites located in areas without evident anthropogenic influence (PS21, PS39, PS46, PS47, and PS58) were generally less contaminated although total CEC concentrations $(1 \mu \mathrm{g} / \mathrm{L})$ in water from PS 39 indicates hidden wastewater impact as a source for the pharmaceuticals acetyl-sulfamethoxazole (A-SMX) and diphenhydramine, and the industrial compound triethycitrate (Fig. 3, Additional file 2: Figures S1-S3). Total CEC concentrations were up to $2 \mathrm{ng} / \mathrm{g}$ OC (mainly triclocarban and DEET) and $228 \mathrm{ng} / \mathrm{g}$ ww in sediments and snails, respectively. Cotinine, efavirenz, atrazine,
$\mathrm{N}$-ethyl-o-toluene sulfonamide, and $\mathrm{N}$-butylbenzenesulfonamide were the compounds contributing to the pollution found in snails. Low contaminant concentrations were observed in sites such as in PS46 located within Homabay County with no immediate impact from anthropogenic activities. In addition, a lot of the farmers in this region practice subsistence farming for household consumption; therefore, less pesticide inputs may be used in the agricultural practices. The site PS 47 is located closely downstream of the Ruma national park, a wildlife reserve with limited human activities.

Agricultural sites such as PS17 and PS18 within sugarcane plantations had high contaminant concentrations in all the three matrices (Fig. 3, Additional file 2: Figures $\mathrm{S} 1-\mathrm{S} 3$ ). Total compound concentrations were up to $11 \mu \mathrm{g} / \mathrm{L}$ in water, $555 \mathrm{ng} / \mathrm{g}$ ww in snails, and $304 \mathrm{ng} / \mathrm{g}$ OC in sediments. Notably, high concentrations were obtained for the PaBs atrazine in snails and pirimiphos-methyl, DEET, and triclocarban in sediments, while 2,4-dichlorophenoxyacetic acid (2,4-D) and hexazinone predominated in water [26]. The high concentrations of pesticides are in agreement with sampling during the spraying period in sugarcane plantations (September-October). Other compounds that contributed to pollution included efavirenz and NETs (in both snails and sediments), while the hydrophilic CECs A-SMX, the sweetener acesulfame, and triethycitrate were found only in water samples from these two sites. The presence of Awendo town nearby could contribute as an important source of these compounds into the aquatic system.

In rice plantation fields (PS25, PS26, PS27, PS28, and Uli15), high total compound concentrations of up to $3.3 \mu \mathrm{g} / \mathrm{L}$ in water, $598 \mathrm{ng} / \mathrm{g} \mathrm{ww}$ in snails, and $22 \mathrm{ng} / \mathrm{g}$ OC in sediments were detected. Similar to sugarcane sites, $\mathrm{PaBs}$ contributed most to the overall pollution with atrazine predominating in snails and triclocarban in sediments. Carbendazim and bendiocarb contributed most to water contamination [26].

Among agricultural areas, sites within tea plantations (PS56, PS57, Uli1, Uli3) were least impacted with pollutants. Total CEC concentrations reached up to $6 \mathrm{ng} / \mathrm{g} \mathrm{OC}$ in sediments with the insect repellant DEET as a major contributor, while no snails were found at these sites. A plausible explanation for the low pesticide contamination is the mismatch of sampling (September and October) and the spraying period in tea plantations (June). Additionally, the streams in tea growing areas are protected by wide buffer zones, while in other agricultural areas, the farmland is much closer to the water bodies leading to higher run-off potential.

In general, the occurrence of PPCPS in agricultural sites shows the evidences of municipal waste impact on 
the local water bodies. For example, the pharmaceuticals efavirenz and 2-hydroxyquinoline were found in high concentrations in snails collected from rice fields. A plausible explanation for the high concentrations found could be the direct discharge of untreated domestic wastewater from residential areas, lack of sanitation facilities, and effluent discharge from wastewater treatment facilities into the river.

\section{Risk assessment based on sediment concentrations}

Based on equilibrium water concentrations calculated from sediment, toxic risks were estimated for fish, crustacean, and algae. For fish, the $\mathrm{TU}_{\text {sum }}$ ranged from $9.1 \times 10^{-8}$ to $1.4 \times 10^{-2}$ (Additional file 1: Table S7, Additional file 2: Figure S4). Pirimiphos-methyl and imidacloprid-urea were identified as risk drivers for fish exposed to sediments in PS17, while diuron is predominating in PS59. Ethyl azinphos contributed greatly to the risk in PS42 and PS43. Maximum TUs were observed for pirimiphos-methyl ( $\mathrm{TU}=0.007)$ and the transformation product imidacloprid-urea $(\mathrm{TU}=0.005)$, but did not exceed the acute and chronic risk thresholds. However, with this low toxic risk on fish observed, it should be mentioned that natural and synthetic estrogenic hormones were not measured in this study. These hormones have been shown to drive effects on fish reproduction in the $\mathrm{ng} / \mathrm{L}$ range, resulting in the collapse of whole fish populations [27]. Estrogens are often emitted with untreated wastewater [30].

Cumulative TUs for crustaceans were generally higher than those obtained for fish (range: $9.6 \times 10^{-8}$ to 1.1 ) with diazinon, fipronil sulfone, and pirimiphos-methyl driving the overall risk (Additional file 1: Table S8, Fig. 5). Maximum $\mathrm{TU}_{\text {sum }}$ was reported for the site PS17 $\left(\mathrm{TU}_{\text {sum }} 1.1\right)$ impacted by the large agro-industrial sugarcane plantation with pirimiphos-methyl $(\mathrm{TU}=0.99)$ and diazinon ( $\mathrm{TU}=0.11)$ driving the risk, both exceeding the ART (TU $>0.1$ ) for crustaceans. The chronic risk threshold of TU $>0.001$ was exceeded at 20 sites for diazinon, at 14 sites for pirimiphos-methyl, and at four sites for fipronil sulfone.

For algae, the cumulative risk was higher than for fish but lower compared to crustaceans. The $\mathrm{TU}_{\text {sum }}$ ranged from $8.7 \times 10^{-7}$ to 0.24 , with the photosynthesis inhibitor diuron driving the risk to algae at most sites (Additional file 1: Table S9, Fig. 6). Diuron is a selective herbicide for the control of weeds in sugarcane plantations [52]. The highest TU values were obtained in sediments from PS59 $(\mathrm{TU}=0.24)$ exceeding ART and PS17 $(\mathrm{TU}=0.03)$ exceeding CRT.

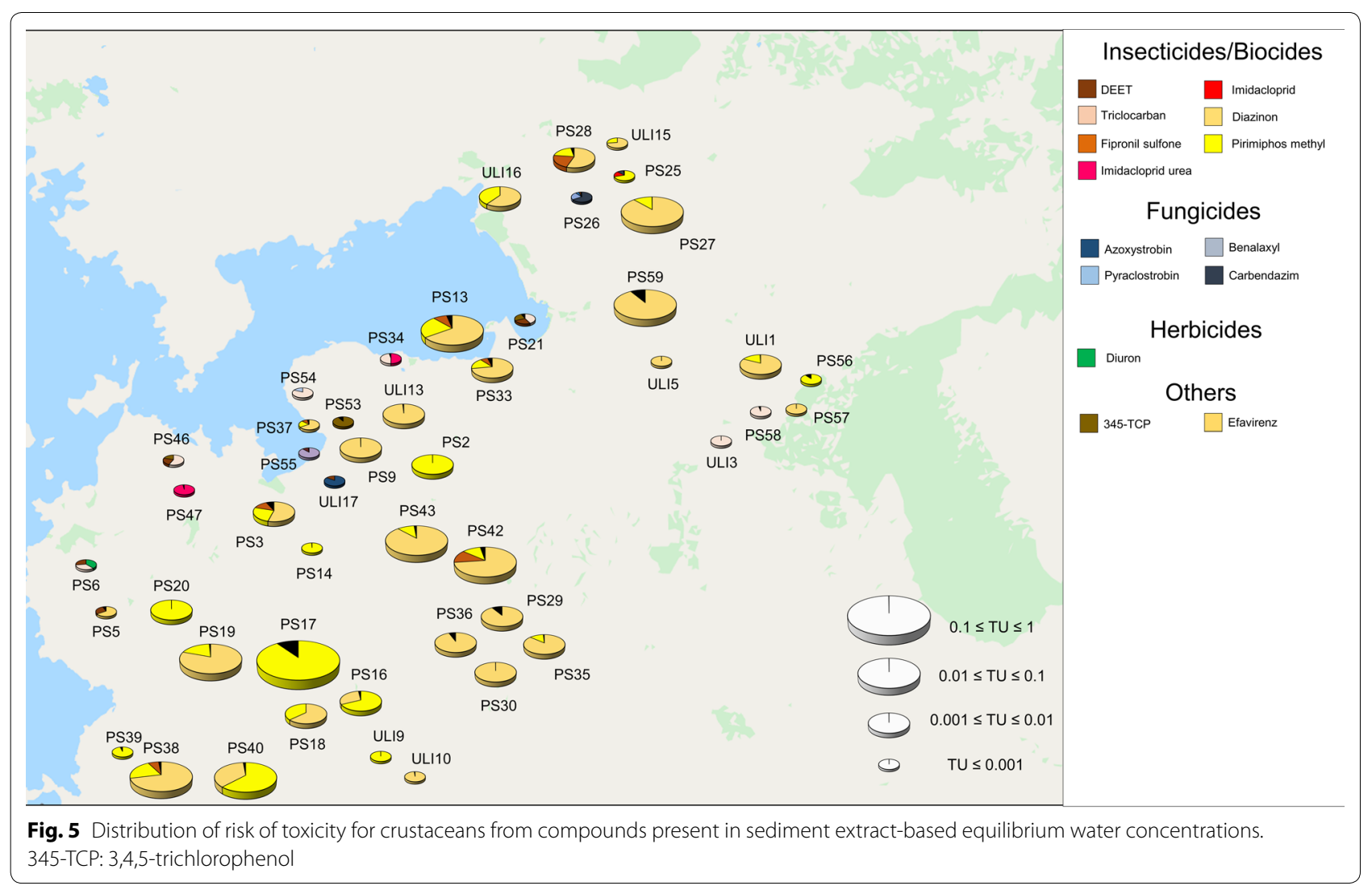




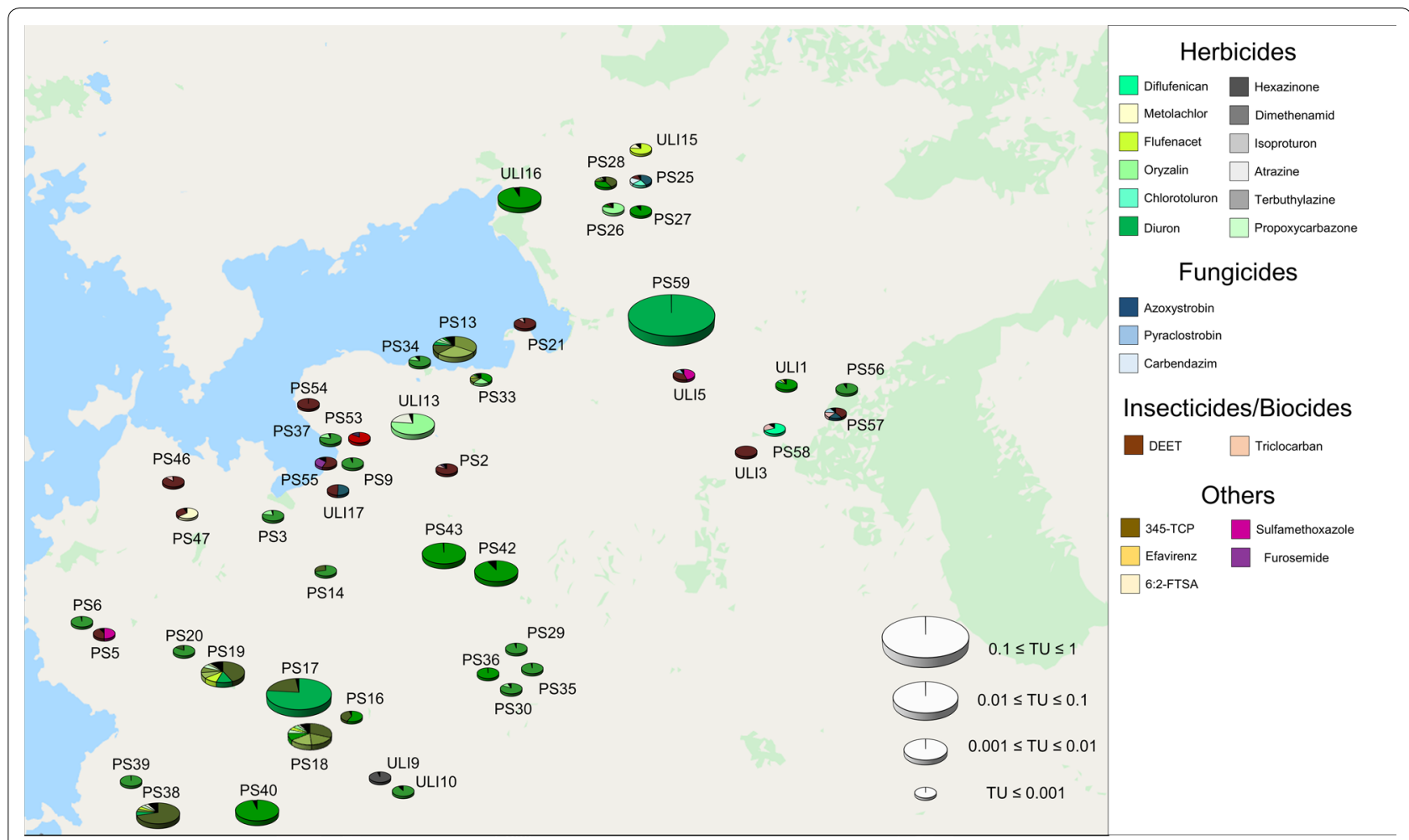

Fig. 6 Distribution of risk of toxicity for algae from compounds present in sediment extract-based equilibrium water concentrations. 345-TCP: 3,4,5-trichlorophenol; 6:2-FTSA: 6:2-fluorotelomer sulfonic acid

\section{Conclusions}

The present study bridges substantial data gaps on the contamination of freshwater habitats in rural areas within western Kenya with CECs. The study demonstrates that complementing water monitoring with the analysis of sediments and biota may strongly increase the number of detectable contaminants allowing for a more comprehensive assessment of pollution. In this study, 66 chemicals were detected only in snails and sediments, while 51 compounds were found exclusively in water. Although common hot spots of contamination were identified in all three matrices, sediments and snails provide a picture that is rather independent of water concentrations measured in randomly taken grab samples. These findings support the complementary monitoring of biota and sediments as time-integrated samplers of pollution.

Although partly confounded by complex land-use structures, contamination of sediments and biota could be linked to specific agricultural production. Pesticide applications in sugarcane plantations and rice fields were important sources of contamination and toxic risks to aquatic organisms. Poorly treated and untreated municipal wastewater and a lack of sanitation may be seen as another highly relevant source of pollution with pharmaceuticals and personal care products.
Very high toxic risks due to contaminated sediments were found for crustaceans in some of the sites, with diazinon and pirimiphos-methyl driving this risk. Substantial acute and chronic risk was also observed for algae mainly driven by diuron, while fish suffered only low toxic risk. Sublethal effects such as endocrine disruption and other specific effects by natural and synthetic steroids and pharmaceuticals discharged with untreated wastewater could not be considered in this study, but might be more relevant for fish populations than acute toxicity. Future studies should focus on potential toxicological risk to humans and wildlife resulting from bioaccumulation and biomagnification of certain contaminants due to the consumption of contaminated food.

Overall, this study indicates substantial contamination of rural areas in western Kenya and promotes systematic monitoring and assessment of CECs in different matrices to characterize and mitigate risks to ecosystems but also human health.

\section{Supplementary information}

Supplementary information accompanies this paper at https://doi. org/10.1186/s12302-020-00392-9.

Additional file 1. Additional tables. 
Additional file 2. Supplementary information.

\section{Abbreviations}

ART: Acute risk threshold; CRT: Chronic risk threshold; CECs: Chemicals of emerging concern; $C_{\text {ewsed: }}$ : Equilibrium water concentrations; $C_{\text {sed: }}$ : Sediment organic carbon; DCM: Dichloromethane; EC: Effect concentrations; $K_{o c}$ : Organic carbon-water partitioning coefficients; LC-HRMS: Liquid chromatography-high-resolution mass spectrometry; LVSB: Lake Victoria South Basin; PLE: Pressurized liquid extraction; PPCPs: Pharmaceuticals and personal care products; PSA: Primary secondary amine; QuEChERS: Quick, easy, cheap, effective, rugged, and safe; TOC: Organic carbon contents; TU: Toxic units.

\section{Acknowledgements}

We are thankful to Paul Ouma for the support during sampling. A free academic license of JChem for Office (Excel) was used for structure-based property calculations -Jchem 17.21.0, 2019 ChemAxon (https://www.chema xon.com), which we gratefully acknowledge. Google My Maps was used to create maps to indicate the site locations (https://www.google.com/maps/d/). The QExactive Plus LC-HRMS used is part of the major infrastructure initiative CITEPro (Chemicals in the Terrestrial Environment Profiler) funded by the Helmholtz Association. We also gratefully acknowledge the financial support for this research by icipe's core donors including the UK's Department for International Development (DFID); the Swedish International Development Cooperation Agency (Sida); the Swiss Agency for Development and Cooperation (SDC); the Federal Democratic Republic of Ethiopia; and the Kenyan Government.

\section{Authors' contributions}

$F K, M K, A G, B T, U L, J B, M L$, and WB designed the research; FK and AG conducted the research; FK, MK, and RM analyzed and interpreted the data; FK drafted the initial version; MK, RM, and WB edited and reviewed; FK, MK, RM, $A G, B T, U L, J B, M L$, and $W B$ contributed to the final version. All authors read and approved the final manuscript.

\section{Funding}

This work was funded by the Deutsche Forschungsgemeinschaft (DFG) under project SENTINEL [Grant Numbers LI 1708/4-1, BR 2931/3-1, HO 3330/12-1]. Open access funding provided by Projekt DEAL.

\section{Availability of data and materials}

The datasets supporting the conclusions of this article are included within the article and its additional files.

\section{Ethics approval and consent to participate}

Compliance with relevant national and institutional guidelines, and appropriate permissions were obtained and followed during this study.

\section{Consent for publication}

Not applicable.

\section{Competing interests}

The authors declare that they have no competing interests.

\section{Author details}

1 Department of Effect-Directed Analysis, Helmholtz Centre for Environmental Research (UFZ), Permoserstrasse 15, 04318 Leipzig, Germany. ${ }^{2}$ International Centre of Insect Physiology and Ecology (Icipe), P.O. Box 30772-00100, Nairobi, Kenya. ${ }^{3}$ Department of Evolutionary Ecology and Environmental Toxicology, Faculty of Biological Sciences, Goethe University Frankfurt, Max-von-Laue-Strasse. 13, 60438 Frankfurt am Main, Germany. ${ }^{4}$ Department of Biological Sciences, Moi University, P.O. Box 3900-30100, Eldoret, Kenya. ${ }^{5}$ Department of Biological Sciences, Egerton University, P.O. Box 536, Egerton, Kenya. ${ }^{6}$ Department of System Ecotoxicology, Helmholtz Centre for Environmental Research (UFZ), Permoserstrasse 15, 04318 Leipzig, Germany. ${ }^{7}$ Department of Ecosystem Analysis, Institute for Environmental Research, RWTHAachen University, Worringerweg 1, 52074 Aachen, Germany. ${ }^{8}$ Present Address: Veterinary Physiology and Biochemistry, Department of Veterinary Sciences, University of Antwerp, Universiteitsplein 1, 2610 Wilrijk, Belgium.
Received: 26 June 2020 Accepted: 19 August 2020

Published online: 08 September 2020

\section{References}

1. Altenburger R, Nendza M, Schüürmann G (2003) Mixture toxicity and its modeling by quantitative structure-activity relationships. Environ Toxicol Chem 22:1900-1915

2. Ashauer R, Agatz A, Albert C, Ducrot V, Galic N, Hendriks J, Jager T, Kretschmann A, O'Connor I, Rubach MN, Nyman AM, Schmitt W, Stadnicka J, van den Brink PJ, Preuss TG (2011) Toxicokinetic-toxicodynamic modeling of quantal and graded sublethal endpoints: a brief discussion of concepts. Environ Toxicol Chem 30:2519-2524

3. Aus der Beek T, Weber F-A, Bergmenn A, Hickmann S, Ebert I, Hein A, Küster A (2016) Pharmaceuticals in the environment-global occurences and perspectives. Environ Toxicol Chem 35:823-835

4. Backhaus T, Faust M (2012) Predictive environmental risk assessment of chemical mixtures: a conceptual framework. Environ Sci Technol 46:2564-2573

5. Bagnis S, Boxall A, Gachanja A, Fitzsimons M, Murigi M, Snape J, Tappin A, Wilkinson J, Comber S (2020) Characterization of the Nairobi River catchment impact zone and occurrence of pharmaceuticals: implications for an impact zone inclusive environmental risk assessment. Sci Total Environ 703:134925

6. Bandow NR, Streck AG, Brack W (2009) Effect-directed analysis of contaminated sediments with partition-based dosing using green algae cell multiplication inhibition. Environ Sci Technol 43(19):7343-7349

7. Bashir IM, Nyakoe N, Van Der Sande M (2019) Targeting remaining pockets of malaria transmission in Kenya to hasten progress towards national elimination goals: an assessment of prevalence and risk factors in children from the Lake endemic region. Malar J 18:1-10

8. Becker JM, Ganatra AA, Kandie F, Mühlbauer L, Ahlheim J, Brack W, Torto B, Agola EL, McOdimba F, Hollert H, Fillinger U, Liess M (2020) Pesticide pollution in freshwater paves the way for schistosomiasis transmission. Sci Rep 10:136748

9. Blais JM, Macdonald RW, Mackay D, Webster E, Harvey C, Smol JP (2007) Biologically mediated transport of contaminants to aquatic systems. Environ Sci Technol 41:1075-1084

10. Busch W, Schmidt S, Kühne R, Schulze T, Krauss M, Altenburger R (2016) Micropollutants in European rivers: a mode of action survey to support the development of effect-based tools for water monitoring. Environ Toxicol Chem 35:1887-1899

11. Ccanccapa A, Masiá A, Navarro-Ortega A, Picó Y, Barceló D (2016) Pesticides in the Ebro River basin: occurrence and risk assessment. Environ Pollut 211:414-424

12. Contardo-Jara V, Lorenz C, Pflugmacher S, Nützmann G, Kloas W, Wiegand C (2011) Exposure to human pharmaceuticals Carbamazepine, Ibuprofen and Bezafibrate causes molecular effects in Dreissena polymorpha. Aquat Toxicol 105:428-437

13. de Almeida ACG, Petersen K, Langford K, Thomas KV, Tollefsen KE (2017) Mixture toxicity of five biocides with dissimilar modes of action on the growth and photosystem II efficiency of Chlamydomonas reinhardtii. J Toxicol Environ Health Part A 80:971-986

14. Di Toro DM, Zarba CS, Hansen DJ, Berry WJ, Swartz RC, Cowan CE, Pavlou SP, Allen HE, Thomas NA, Paquin PR (1991) Technical basis for establishing sediment quality criteria for nonionic organic chemicals using equilibrium partitioning. Environ Toxicol Chem 10:1541-1583

15. Duncan M, Fried B, Sherma J (1987) Lipids in fed and starved Biomphalaria glabrata (gastropoda). Comp Biochem Physiol 86A:663-665

16. Ekpe E, Shaikh AJ, Shah J, Jacobson JS, Sayed S (2019) Metastatic breast cancer in Kenya: presentation, pathologic characteristics, and patternsfindings from a Tertiary Cancer Center. J Glob Oncol 5:1-11

17. Getenga Z, Keng'ara F, Wandiga S (2004) Determination of organochlorine pesticide residues in soil and water from River Nyando drainage system within Lake Victoria Basin, Kenya. Environ Contam Toxicol 72:335-343

18. Guo J, Sinclair CJ, Selby K, Boxall ABA (2016) Toxicological and ecotoxicological risk-based prioritization of pharmaceuticals in the natural environment. Environ Toxicol Chem 35:1550-1559 
19. Halstead ANT, Hoover CM, Arakala A, Civitello DJ (2018) Agrochemical pollution increases risk of human exposure to schistosome parasites. Nat Commun 9:1-10

20. Heim S, Schwarzbauer J (2013) Pollution history revealed by sedimentary records: a review. Environ Chem Lett 11:255-270

21. Inostroza PA, Massei R, Wild R, Krauss M, Brack W (2017) Chemical activity and distribution of emerging pollutants: insights from a multi-compartment analysis of a freshwater system. Environ Pollut 231:339-347

22. Inostroza PA, Wicht AJ, Huber T, Nagy C, Brack W, Krauss M (2016) Body burden of pesticides and wastewater-derived pollutants on freshwater invertebrates: method development and application in the Danube River. Environ Pollut 214:77-85

23. K'oreje KO, Kandie FJ, Vergeynst L, Abira MA, Van Langenhove H, Okoth M, Demeestere K (2018) Occurrence, fate and removal of pharmaceuticals, personal care products and pesticides in wastewater stabilization ponds and receiving rivers in the Nzoia Basin, Kenya. Sci Total Environ 637-638:336-348

24. K'oreje KO, Okoth M, Van Langenhove H, Demeestere K (2020) Occurrence and treatment of contaminants of emerging concern in the African aquatic environment: literature review and a look ahead. J Environ Manag 254:109752

25. Kairigo P, Ngumba E, Sundberg LR, Gachanja A, Tuhkanen T (2020) Occurrence of antibiotics and risk of antibiotic resistance evolution in selected Kenyan wastewaters, surface waters and sediments. Sci Total Environ 720:137580

26. Kandie F, Krauss M, Beckers L, Massei R, Fillinger U, Becker J, Liess M, Torto B, Brack W (2020) Occurrence and risk assessment of organic micropollutants in freshwater systems within the Lake Victoria South Basin, Kenya. Sci Total Environ 714:1-13

27. Kidd KA, Blanchfield PJ, Mills KH, Palace VP, Evans RE, Lazorchak JM, Flick RW (2007) Collapse of a fish population after exposure to a synthetic estrogen. Proc Natl Acad Sci USA 104:8897-8901

28. Kimosop SJ, Getenga ZM, Orata F, Okello VA, Cheruiyot JK (2016) Residue levels and discharge loads of antibiotics in wastewater treatment plants (WWTPs), hospital lagoons, and rivers within Lake Victoria Basin, Kenya. Environ Monit Assess 188:1-9

29. Köhler HR, Triebskorn R (2013) Wildlife ecotoxicology of pesticides: Can we track effects to the population level and beyond? Science 341:759-765

30. König M, Escher BI, Neale PA, Krauss M, Hilscherová K, Novák J, Teodorović I, Schulze T, Seidensticker S, Kamal Hashmi MA, Ahlheim J, Brack W (2017) Impact of untreated wastewater on a major European river evaluated with a combination of in vitro bioassays and chemical analysis. Environ Pollut 220:1220-1230

31. Kreitchmann R, Schalkwijk S, Best B, Wang J, Colbers A, Stek A, Shapiro D, Cressey T, Mirochnick M, Burger D (2019) Efavirenz pharmacokinetics during pregnancy and infant washout. Antivir Ther 24:95-103

32. Li H, Cheng F, Wei Y, Lydy MJ, You J (2017) Global occurrence of pyrethroid insecticides in sediment and the associated toxicological effects on benthic invertebrates: an overview. J Hazard Mater 324:258-271

33. Liess M, Von Der Ohe PC (2005) Analyzing effects of pesticides on invertebrate communities in streams. Environ Toxicol Chem 24:954-965

34. Loewe S, Muischnek H (1926) Über kombinationswirkungen. 1. Mitteilung: hilfsmittel der fragestellung. Naunyn-Schmiedebergs Arch Exp Pathol Und Pharmakologie 114:313-326

35. Luo Y, Guo W, Ngo HH, Nghiem LD, Hai Fl, Zhang J, Liang S, Wang XC (2014) A review on the occurrence of micropollutants in the aquatic environment and their fate and removal during wastewater treatment. Sci Total Environ 473-474:619-641

36. Mackay D, Arnot JA, Wania F, Bailey RE (2011) Chemical activity as an integrating concept in environmental assessment and management of contaminants. Integr Environ Assess Manag 7:248-255

37. Malaj E, Von Der Ohe PC, Grote M, Kühne R, Mondy CP, Usseglio-Polatera P, Brack W, Schäfer RB (2014) Organic chemicals jeopardize the health of freshwater ecosystems on the continental scale. Proc Natl Acad Sci 111:9549-9554

38. Masiá A, Campo J, Vázquez-Roig P, Blasco C, Picó Y (2013) Screening of currently used pesticides in water, sediments and biota of the Guadalquivir River Basin (Spain). J Hazard Mater 263:95-104

39. Massei R, Byers H, Beckers LM, Prothmann J, Brack W, Schulze T, Krauss M (2018) A sediment extraction and cleanup method for wide-scope multitarget screening by liquid chromatography-high-resolution mass spectrometry. Anal Bioanal Chem 410:177-188
40. Mayer P, Holmstrup M (2008) Passive dosing of soil invertebrates with polycyclic aromatic hydrocarbons: limited chemical activity explains toxicity cutoff. Environ Sci Technol 42:7516-7521

41. Merhaby D, Rabodonirina S, Net S, Ouddane B, Halwani J (2019) Overview of sediments pollution by PAHs and PCBs in mediterranean basin: transport, fate, occurrence, and distribution. Mar Pollut Bull 149:110646

42. Monde C, Syampungani S, Van den Brink PJ (2016) Effects of endosulfan on predator-prey interactions between catfish and schistosoma host snails. Arch Environ Contam Toxicol 71:257-266

43. Musa S, Gichuki JW, Raburu PO, Aura CM (2011) Risk assessment for organochlorines and organophosphates pesticide residues in water and sediments from lower Nyando/Sondu-Miriu river within Lake Victoria Basin, Kenya. Lakes Reserv Res Manag 16:273-280

44. Mzukisi L, Tawanda N, Chimuka L (2017) Status of pharmaceuticals in African water bodies: occurrence, removal and analytical methods. J Environ Manag 193:211-220

45. National AIDS Control Council NACC (2018) Ministry of Health National AIDS Control Council. In: Minist. Heal. http://www.Ivcthealth.org/wpcontent/uploads/2018/11/KARPR-Report_2018.pdf. http://www.nacc. or.ke. Accessed 30 Apr 2020

46. Nendza M, Herbst T, Kussatz C, Gies A (1997) Potential for secondary poisoning and biomagnification in marine organisims. Chemosphere 35:1875-1885

47. Ngumba E, Gachanja A, Tuhkanen T (2016) Occurrence of selected antibiotics and antiretroviral drugs in Nairobi River Basin, Kenya. Sci Total Environ 539:206-213

48. Nhan DD, Carvalho FP, Am NM, Tuan NQ, Yen NTH, Villeneuve JP, Cattini C (2001) Chlorinated pesticides and PCBs in sediments and molluscs from freshwater canals in the Hanoi region. Environ Pollut 112:311-320

49. Oehlmann J, Schulte-Oehlmann U (2003) Chapter 17 Molluscs as bioindicators. In: Trace metals and other contaminants in the environment. pp 577-635

50. Osoro E, Wandiga S, Abongo D, Madadi VO, Macharia JW (2016) Organochlorine pesticides residues in water and sediment from Rusinga Island, Lake Victoria, Kenya. J Appl Chem 9:56-63

51. Otieno P, Okinda Owuor P, Lalah JO, Pfister G, Schramm K-W (2015) Monitoring the occurrence and distribution of selected organophosphates and carbamate pesticide residues in the ecosystem of Lake Naivasha, Kenya. Toxicol Environ Chem 97:51-61

52. Pest Control Products Board (2018) Pest Control Products registered for use in Kenya. In: https://www.pcpb.go.ke/crops/. Accessed 26 Feb 2020

53. Petersen GO, Leite CE, Chatkin JM, Thiesen FV (2010) Cotinine as a biomarker of tobacco exposure: development of a HPLC method and comparison of matrices. J Sep Sci 33:516-521

54. Pluskal T, Castillo S, Villar-Briones A, Orešič M (2010) MZmine 2: modular framework for processing, visualizing, and analyzing mass spectrometrybased molecular profile data. BMC Bioinform 11:395

55. Sprague JB (1970) Measurement of pollutant toxicity to fish. Il. Utilizing and applying bioassay results. Water Res 4:3-32

56. Sui Q, Cao X, Lu S, Zhao W, Qiu Z, Yu G (2015) Occurrence, sources and fate of pharmaceuticals and personal care products in the groundwater: a review. Emerg Contam 1:14-24

57. Thomas K, Schlabach M, Langford K, Fjeld E, Øxnevad S, Rundberget, Thomas Bæk K, Rostkowski P, Harjuand M (2014) Screening program 2013: new bisphenols, organic peroxides, fluorinated siloxanes, organic UV filters and selected PBT substances. Oslo

58. Ulrich N, Endo S, Brown T, Watanabe N, Bronner G, Abraham MH, Goss K-U (2017) UFZ-LSER database v 3.2.1 [Internet], Leipzig, Germany. Helmholtz Centre for Environmental Research-UFZ., V 3.2.1. http://www.ufz.de//serd

59. Wandiga SO, Yugi PO, Barasa MW, Jumba IO, Lalah JO (2002) The distribution of organochlorine pesticides in marine samples along the Indian ocean coast of Kenya. Environ Technol 23:1235-1246

60. Yin G, Zhou Y, Strid A, Zheng Z, Bignert A, Ma T, Athanassiadis I, Qiu $Y$ (2017) Spatial distribution and bioaccumulation of polychlorinated biphenyls (PCBs) and polybrominated diphenyl ethers (PBDEs) in snails (Bellamya aeruginosa) and sediments from Taihu Lake area, China. Environ Sci Pollut Res 24:7740-7751

\section{Publisher's Note}

Springer Nature remains neutral with regard to jurisdictional claims in published maps and institutional affiliations. 